\title{
EFFECTS OF MONOCULAR DEPRIVATION ON THE STRUCTURE- FUNCTION RELATIONSHIP OF INDIVIDUAL NEURONS IN THE CAT'S LATERAL GENICULATE NUCLEUS ${ }^{1}$
}

\author{
MICHAEL J. FRIEDLANDER, ${ }^{*, 2}$ L. R. STANFORD, $\ddagger$ AND S. MURRAY SHERMAN \\ $¥$ Department of Neurobiology and Behavior, State University of New York at Stony Brook, Stony Brook, New York 11794 \\ and ${ }^{*}$ Department of Physiology and Biophysics, University of Alabama in Birmingham, Birmingham, Alabama 352.94
}

Received August 19, 1981; Accepted October 29, 1981

\begin{abstract}
The retino-geniculo-cortical pathways of the cat are composed of at least three parallel channels. The neurons in these channels (W-, X-, and Y-cells) have different physiological properties. In earlier studies, we used a direct structure-function analysis for individual geniculate neurons in normal cats. This was accomplished by electrophysiological characterization of the neuron followed by intracellular iontophoresis of horseradish peroxidase into the same neuron. By this technique, we demonstrated that W-, X-, and Y-cells have distinctive morphological features in the lateral geniculate nucleus of the cat. We have extended this analysis in cats reared with monocular eyelid suture to 24 geniculate neurons innervated by the sutured eye in lamina $\mathrm{A}$ or $\mathrm{A}_{1}$. Ten of the 24 neurons $(42 \%)$ had abnormal structure-function relationships. All but 1 of the normal cells were $\mathrm{X}$ cells. Abnormalities included: (1) Y-cells with normal physiology but abnormally small somata; (2) Y-cells with abnormal physiology and morphology, including poor responsiveness and unusually thin, tortuous, and beaded dendrites; (3) visually unresponsive cells with morphology similar to that of the physiologically abnormal Y-cells; and (4) cells with the physiology of normal X-cells but the morphology of normal Y-cells. Furthermore, soma size measurements indicate that the abnormally small somata found in deprived geniculate laminae result from a selective effect on Y-cells.
\end{abstract}

Early monocular eyelid suture causes a number of deficits in developing neurons in the central visual pathways of the cat. Many of these deficits occur in the dorsal lateral geniculate nucleus among neurons in deprived laminae (i.e., those receiving inputs from the sutured eye). These effects include: abnormally small somata (Wiesel and Hubel, 1963; Guillery and Stelzner, 1970; Guillery, 1972; Garey et al., 1973; Hickey et al., 1977; Kratz et al., 1978b; Hickey, 1980; Kalil, 1980); abnormal receptive fields for some neurons (Wiesel and Hubel, 1963; Kratz et al., 1978b); a reduced proportion of recorded Y-cells (Sherman et al., 1972, 1975; Kratz et al., 1978b; Eysel et al., 1979; Geisert et al., 1980; Mower et al., 1981; Zetlan et al., 1981); reduced responsiveness for Y-cells (Derrington and Hawken, 1981); a reduction in geniculocortical connections, particularly for Y-cells (Lin

\footnotetext{
${ }^{1}$ This work was supported by United States Public Health Service Grants EY03038 (S. M. S.) and EY03805 (M. J. F.). We thank Sally Gibson, Joan Sommermeyer, and Phyllis Turner for their technical assistance.

${ }^{2}$ To whom reprint requests should be addressed at Department of Physiology and Biophysics, 401 Volker Hall, University of Alabama in Birmingham, Birmingham, AL 35294.
}

and Sherman, 1978); and for X-cells, poor contrast sensitivity to visual stimuli with high spatial frequencies (Hoffmann and Sireteanu, 1977; Lehmkuhle et al., 1980b; but see Shapley and So, 1980; Derrington and Hawken, 1981). To our knowledge, no data are available regarding either the dendritic morphology of deprived geniculate neurons or the relationships between structure and function for these cells. The present study was designed to establish directly what, if any, relationships exist between structural and physiological abnormalities for these neurons.

The same techniques that we previously applied to the study of relationships between structure and function among individual neurons in the normal cat's lateral geniculate nucleus (Friedlander et al., 1979, 1981; Stanford et al., 1981) were used in the present study. We used micropipettes filled with horseradish peroxidase (HRP) to obtain physiological data extra- and intracellularly from a single cell, and HRP then was iontophoresed into that cell. Subsequent histochemical processing provided a detailed, Golgi-like morphological view of the physiologically identified cell, and thus, a direct comparison could be made between the structure and function of individual neurons. From such an approach, we described 

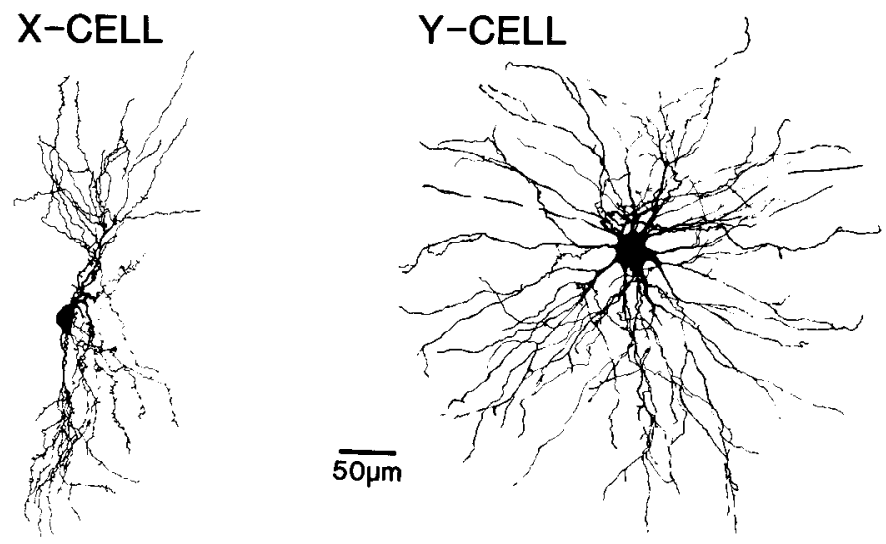

Figure 1. Camera lucida drawings of a typical X-and Y-cell from the lateral geniculate nucleus of normal adult cats. These neurons were injected intracellularly with HRP following physiological classification. The geniculate laminae run horizontally through the figure, parallel to the scale, and this same orientation is maintained in all subsequent drawings. The $\mathrm{X}$-cell is located in lamina $A$ and has a small soma $\left(282 \mu \mathrm{m}^{2}\right.$ in crosssectional area). The vertically oriented dendritic tree is contained entirely within the lamina. Also, the cell's dendrites are thin and sinuous and contain many complex appendages. The large $\mathrm{Y}$-cell soma $\left(760 \mu \mathrm{m}^{2}\right)$ is located in lamina $A_{1}$. Its thick, fairly straight dendrites are radially arranged around the soma, and they are nearly devoid of appendages. Many of the dorsal dendrites cross into lamina A. See Friedlander et al. (1981) for a more complete description of these cells, particularly Figure 6 of that paper for the X-cell and Figure 12 for the Y-cell.

the morphology of geniculate X- and Y-cells in laminae $\mathrm{A}$ and $\mathrm{A}_{1}$ of the normal cat (Friedlander et al., 1979, 1981).

Figure 1 shows representative drawings of an $\mathrm{X}$ - and $\mathrm{Y}$-cell from normal cats. X-cells tend to have smaller somata, thinner axons and dendrites, and dendritic trees oriented perpendicular to the lamination but contained completely within one lamina. Their dendrites tend to be sinuous and contain many complex appendages. These appendages may occur anywhere along the dendrites, but in some X-cells, they cluster near dendritic branch points. Most X-cells thus exhibit class 2 and/or class 3 morphology as defined by Guillery (1966) from Golgi-impregnated material. Y-cells have larger somata, thicker axons, and more radially symmetric dendritic arbors. These features are characteristic of the morphological class 1 cell described by Guillery (1966). Each normal geniculocortical Y-cell has some dendrites that cross laminar borders. Dendritic appendages on Y-cells are relatively rare and simple structures, although a few normal Y-cells have complex grape-like appendages near dendritic branch points and thus fall into the class 2 morphological group of Guillery (1966).

We found that many neurons in deprived laminae $A$ and $\mathrm{A}_{1}$ do not exhibit these normal relationships between structure and function. Several kinds of abnormalities develop. A detailed, comprehensive analysis of these abnormalities will require more data from ongoing studies. This report describes some of the more dramatic abnormalities that develop in morphology and response properties for single geniculate neurons during monocular deprivation.

\section{Materials and Methods}

Except for rearing of the animals, all surgical, electrophysiological, histological, and analytical techniques used in these studies have been described in detail previously (Hoffmann et al., 1972; Friedlander et al., 1979, 1981; Lehmkuhle et al., 1980a, b; Stanford et al., 1981). Consequently, these procedures will be only briefly outlined below.

Subjects. We studied geniculate neurons from 21 kittens born and reared in our laboratory colony. For each kitten, the eyelids were sutured closed over one eye at or before the time of natural eye opening (i.e., 6 to 9 days of age) and were kept closed until the recording session. The kittens were checked daily to ensure complete eyelid closure. All but 3 of the kittens were raised to 12 months of age before study; the other 3 kittens were studied at $4 \frac{1}{2}$ months of age.

Electrophysiological procedures. Cats were anesthetized with halothane for all surgical procedures, and a long lasting, local anesthetic was infused into all wound margins and pressure points. Following the surgical procedures, and for the remainder of the recording session, the cats were maintained on a $70 / 30$ mixture of nitrous oxide/oxygen. The cats were paralyzed and artificially ventilated. End tidal carbon dioxide was monitored and kept near $4.0 \%$, and body temperature was maintained at $37.5^{\circ} \mathrm{C}$. The deprived eye was opened at the beginning of the recording session and inspected to be certain that no ocular abnormalities had developed. The pupils were dilated and the nictitating membranes were retracted with topical application of atropine and phenylephrine. The corneas were covered by contact lenses. Retinoscopy was performed and appropriate spectacle lenses were used to make the retinae conjugate with the visual stimuli.

Bipolar stimulating electrodes of insulated tungsten wire were placed in the optic chiasm to activate geniculate neurons. Single unit activity was recorded with micropipettes filled with 3 to 5\% HRP (Sigma VI) and 0.2 M KCl in $0.05 \mathrm{M}$ Tris at a $\mathrm{pH}$ of 7.0 or 7.4. The electrodes were beveled to a final impedance of 100 to 150 megohms at $100 \mathrm{~Hz}$. The final tip diameter was 0.2 to $0.5 \mu \mathrm{m}$ as estimated from scanning electron micrographs of other microelectrodes that we manufactured with the same procedures.

Electrical stimuli delivered through the optic chiasm electrodes were pulses of up to $5 \mathrm{~mA}$ in amplitude and 50 to $100 \mu \mathrm{sec}$ in duration. Response latency to optic chiasm stimulation was measured as the interval between the shock artifact and the "foot" of the action potential. Responses always displayed some "jitter" or a latency range. A cell's latency was taken as the mode of this range.

Visual stimuli consisted of hand-held light or dark targets and counterphased, sine wave gratings generated on a cathode ray tube. The gratings had a mean luminance of $38 \mathrm{~cd} / \mathrm{m}^{2}$. Spatial frequency, temporal frequency, spatial phase angle, and contrast (between 0 and $0.6)$ were continuously variable. Recordings were limited to laminae $A$ and $A_{1}$, and since $W$-cells are not found in these laminae (Wilson et al., 1976), these neurons were not studied in these experiments. Receptive fields were 
first hand-plotted on a tangent screen, and center size, eccentricity, center type (on or off center), strength of surround, general responsiveness, and regularity of response were noted. Cells were classified as X-cells, Ycells, unclassified cells, or abnormal cells. X- and Y-cells were identified according to a standard battery of tests (Enroth-Cugell and Robson, 1966; Hoffmann et al., 1972; Hochstein and Shapley, 1976; Wilson et al., 1976; Lehmkuhle et al., 1980a), including: (1) latency to optic chiasm stimulation, (2) linearity of spatial summation to gratings counterphased at $2 \mathrm{~Hz}$ at a spatial frequency just below the cell's spatial resolution, and (3) responsiveness to large, fast moving $\left(>200^{\circ} / \mathrm{sec}\right)$ targets of either contrast (i.e., dark or bright against a gray background). Unclassified cells responded like X-cells on some tests and like Y-cells on other tests. A cell was considered abnormal if it responded poorly, variably, or in a fashion not seen in normal cats (see "Results").

Histological procedures. At the end of the recording session, each cat was given an overdose of barbiturate and immediately perfused transcardially with heparinized saline followed by a fixative including $2 \%$ glutaraldehyde and $1 \%$ paraformaldehyde buffered with phosphate to $\mathrm{pH}$ 7.6. A section of the brain containing the lateral geniculate nucleus was stereotaxically removed and sectioned coronally on a Vibratome at $100 \mu \mathrm{m}$. The tissue then was reacted for the presence of HRP by treating it with $3,3^{\prime}$-diaminobenzidine and $\mathrm{H}_{2} \mathrm{O}_{2}$. Many sections were subsequently counterstained with cresyl echt violet. Cells were traced with a drawing tube attached to a microscope with a $\times 100$ oil immersion objective (numerical aperture, 1.32). A Kodak Wratten 48A (deep blue) filter was used to study cell morphology. This filter greatly enhances the contrast between the HRP-diaminobenzidine reaction product and the background and also optimizes resolution with fairly narrow band, short wavelength light (Friedlander et al., 1979, 1981).

\section{Results}

We obtained structure-function data from 24 geniculate neurons in deprived laminae $A$ and $A_{1}$. Since we most frequently recorded in the nucleus ipsilateral to the deprived eye, only 5 of these neurons were located in lamina $\mathrm{A}$, and 19 were in lamina $\mathrm{A}_{1}$. Control data consist of 63 cells from laminae $A$ and $A_{1}$ of normal cats. Of these, 41 have been morphologically analyzed in some detail (cf., Fig. 2 and Friedlander et al., 1981). The remaining 22 have been evaluated only qualitatively to date. Compared to these normal data, only 13 of the 24 deprived neurons possessed clearly normal structurefunction relationships.

Normal $X$ - and $Y$-cells. Thirteen deprived neurons exhibited normal responses and had morphology appropriate to their response properties (Friedlander et al., 1981). Of these, 12 were X-cells and only 1 was a Y-cell. Figure 2 shows the soma sizes of these cells compared to the normal size distribution.

Interlaminar $X$-cell. An additional X-cell had normal physiological properties but unusual morphology. Its soma was located in the interlaminar zone between laminae $A$ and $A_{1}$. Its receptive field was related to the

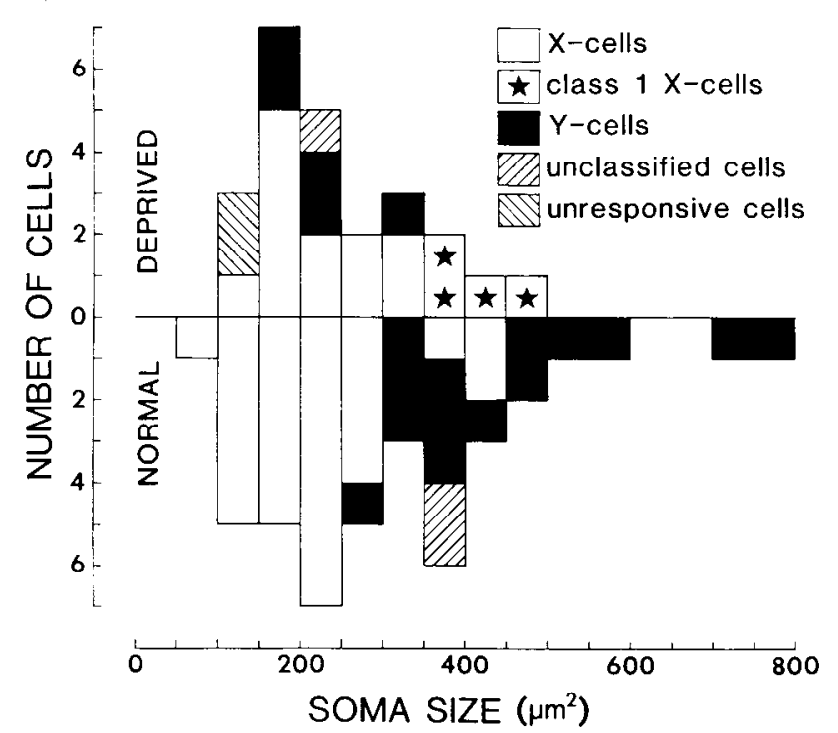

Figure 2. Soma size histograms of geniculate neurons located in laminae $A$ and $A_{1}$ and injected intracellularly with HRP. The upper panel shows the distribution of soma sizes for 24 neurons located in laminae $A$ and $A_{1}$ innervated by the deprived eye of monocularly sutured cats. The lower panel shows the distribution of 41 neurons from normal animals. The normal data for this and succeeding figures are from Friedlander et al. (1981). The deprived Y-cells are significantly smaller than are the normal Y-cells ( $p<0.001$ on a Mann-Whitney $U$ test), but the deprived X-cells are not significantly smaller than are the normal X-cells ( $p>0.1$ on a Mann-Whitney $U$ test).

contralateral, deprived eye, and many dendrites were directed into lamina A. However, much of its dendritic tree ran parallel to the laminar boundaries and was contained within the interlaminar zone. Its soma size and the general morphological appearance of its individual dendrites seem appropriate for normal X-cells. Unfortunately, we have not yet recovered an HRP-filled geniculate cell with an interlaminar soma from a normal animal, although such cells are clearly present in Nissl-stained material. It is thus possible that this cell might represent another deprived X-cell with normal morphology and response properties.

Physiologically normal neurons with abnormally small somata. Two Y-cells responded in a normal fashion to electrical and visual stimulation. They also exhibited normal morphology for Y-cells except for abnormally small somata. Figure 2 includes their soma sizes, and Figure 3 shows tracings of their somata and dendritic arbors. These Y-cells had dendrites with the overall appearance of those from normal $Y$-cells, and their axons innervated the perigeniculate nucleus via collaterals as do those of normal Y-cells. However, their soma sizes were 152 and $245 \mu \mathrm{m}^{2}$ compared to a range of 290 to 790 $\mu \mathrm{m}^{2}$ for HRP-filled Y-cells in laminae $A$ and $A_{1}$ of normal cats.

One physiologically unclassified cell also was recovered. It responded linearly to grating stimuli (i.e., an $\mathrm{X}$-cell feature) but had a short latency $(1.3 \mathrm{msec})$ to optic chiasm stimulation and responded to large dark or bright targets moving faster than $200^{\circ} / \mathrm{sec}$ (i.e., Y-cell features). It had fairly thick dendrites arranged in a radially symmetric fashion around the soma, and few appendages 

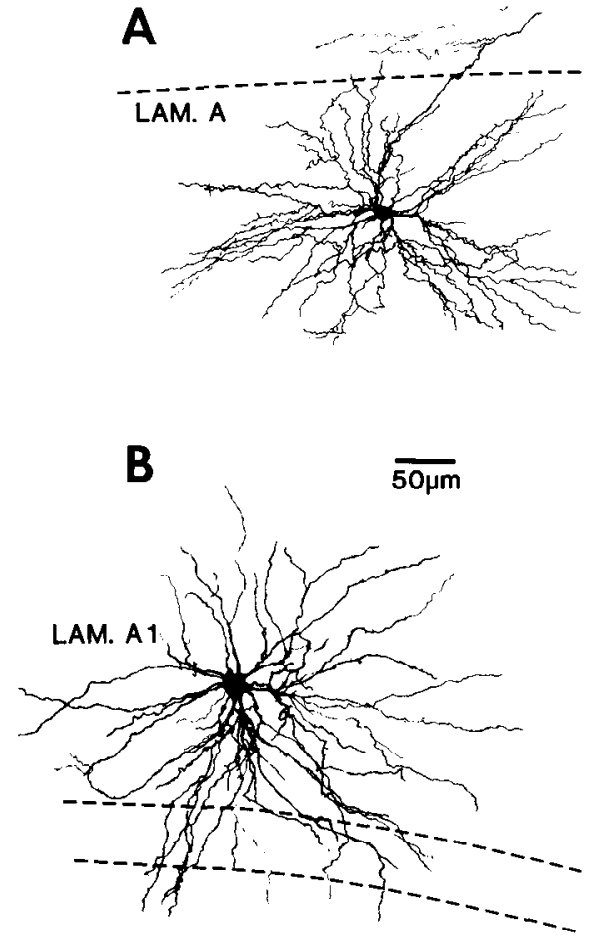

Figure 3. Camera lucida drawings of 2 Y-cells from laminae innervated by the deprived eye in monocularly sutured animals. Laminar boundaries are indicated by the dashed lines. Both of these cells had physiological properties within the range of normal Y-cells. The dendritic morphology also shows a normal $Y$-cell pattern. However, the soma size of each of these deprived $\mathrm{Y}$-cells is smaller than that of any normal Y-cell $\left(152 \mu \mathrm{m}^{2}\right.$ for $A$ and $245 \mu \mathrm{m}^{2}$ for $B$ compared to a range of 290 to $790 \mu \mathrm{m}^{2}$ for normal $\mathrm{Y}$-cells in laminae $\mathrm{A}$ and $\mathrm{A}_{1}$ ). These cells thus appear to have normal $Y$-cell morphology except for their reduced soma sizes.

were found on the dendrites. Such dendritic morphology in normal cats is most commonly associated with Y-cells, but the 2 unclassified cells encountered in normal cats also had this morphological appearance (Friedlander et al., 1981). These cells closely resembled the class 1 morphological type described by Guillery (1966). Nonetheless, the deprived, unclassified cell's soma was not only much smaller than that of every nondeprived unclassified cell (see Fig. 2) but it was also smaller than the soma of every class 1 morphological type seen in normal cats.

Figure 2 shows that no deprived X-cell had a soma smaller than that described by the normal X-cell range.

$Y$-cells with abnormal physiology and morphology. Two cells have been identified physiologically as abnormal Y-cells. They displayed nonlinear spatial summation, responded to large dark or bright targets moving faster than $200^{\circ} / \mathrm{sec}$, and often responded to optic chiasm stimulation at latencies as short as $1.3 \mathrm{msec}$. However, these cells responded inconsistently and generally weakly to these stimuli. The latency range of each cell to optic chiasm stimulation was 1.3 to $1.9 \mathrm{msec}$. This range included a single, broad latency distribution not seen in normal cats rather than a bimodal distribution, indicating both X-and Y-cell optic tract input that sometimes is seen normally (Cleland et al., 1971; Hoffmann et al., 1972). Both of these cells responded irregularly and rapidly fatigued when presented with stationary visual tar- gets, and each exhibited a background pattern of high frequency bursting in the absence of visual stimulation. Such responses are not seen in normal cats. Although only these 2 abnormal cells were filled with HRP suc-
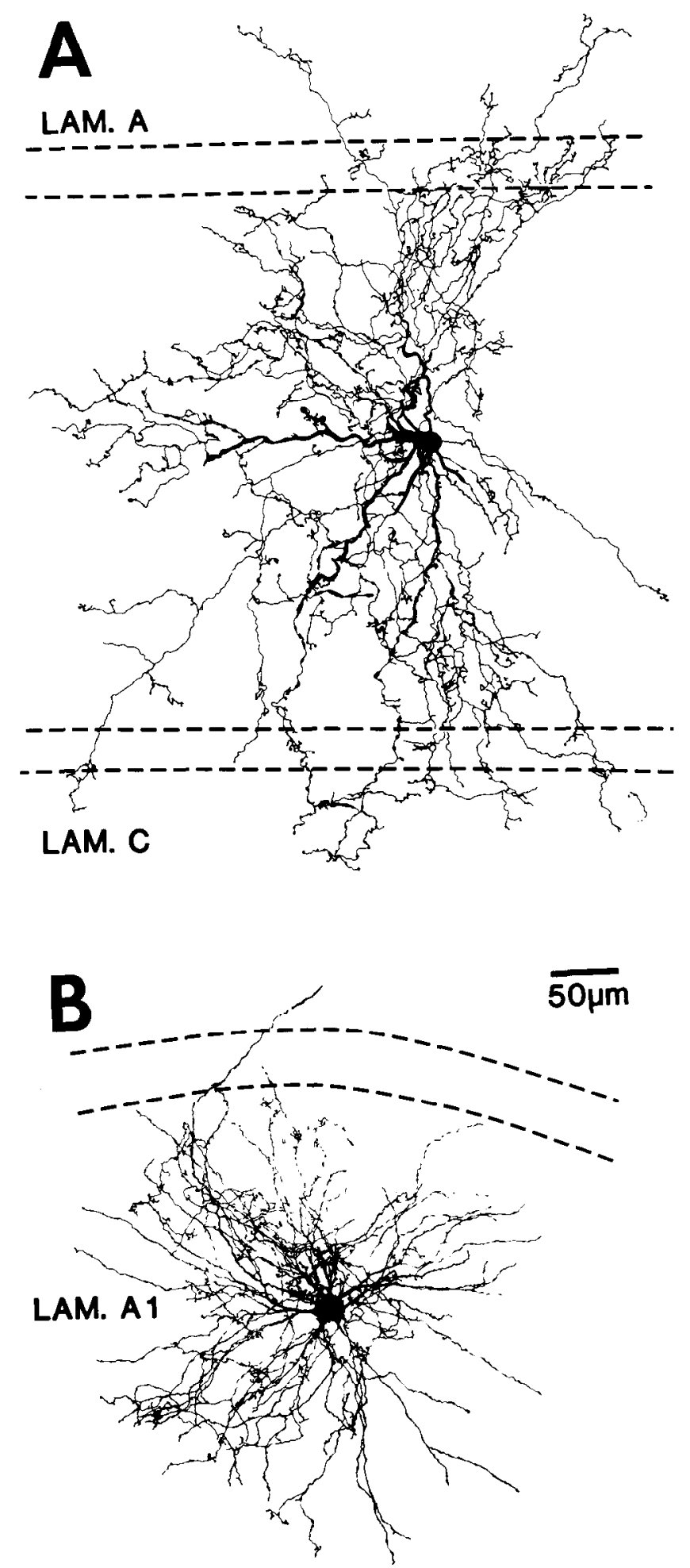

Figure 4. Camera lucida drawings of 2 cells from laminae innervated by the deprived eye of monocularly sutured cats. Both of these cells had abnormal physiological and morphological properties (see text for details). Note the extreme tangling and beading of the dendritic trees beyond the relatively thick and straight proximal dendrites. Also, each soma is smaller $\left(<250 \mu \mathrm{m}^{2}\right)$ than any normal Y-cell. Laminar boundaries are indicated by the dashed lines. 
cessfully, other similar cells were encountered during these experiments.

The morphological features of these cells were quite abnormal as shown by Figures 4 and 5 . The somata of
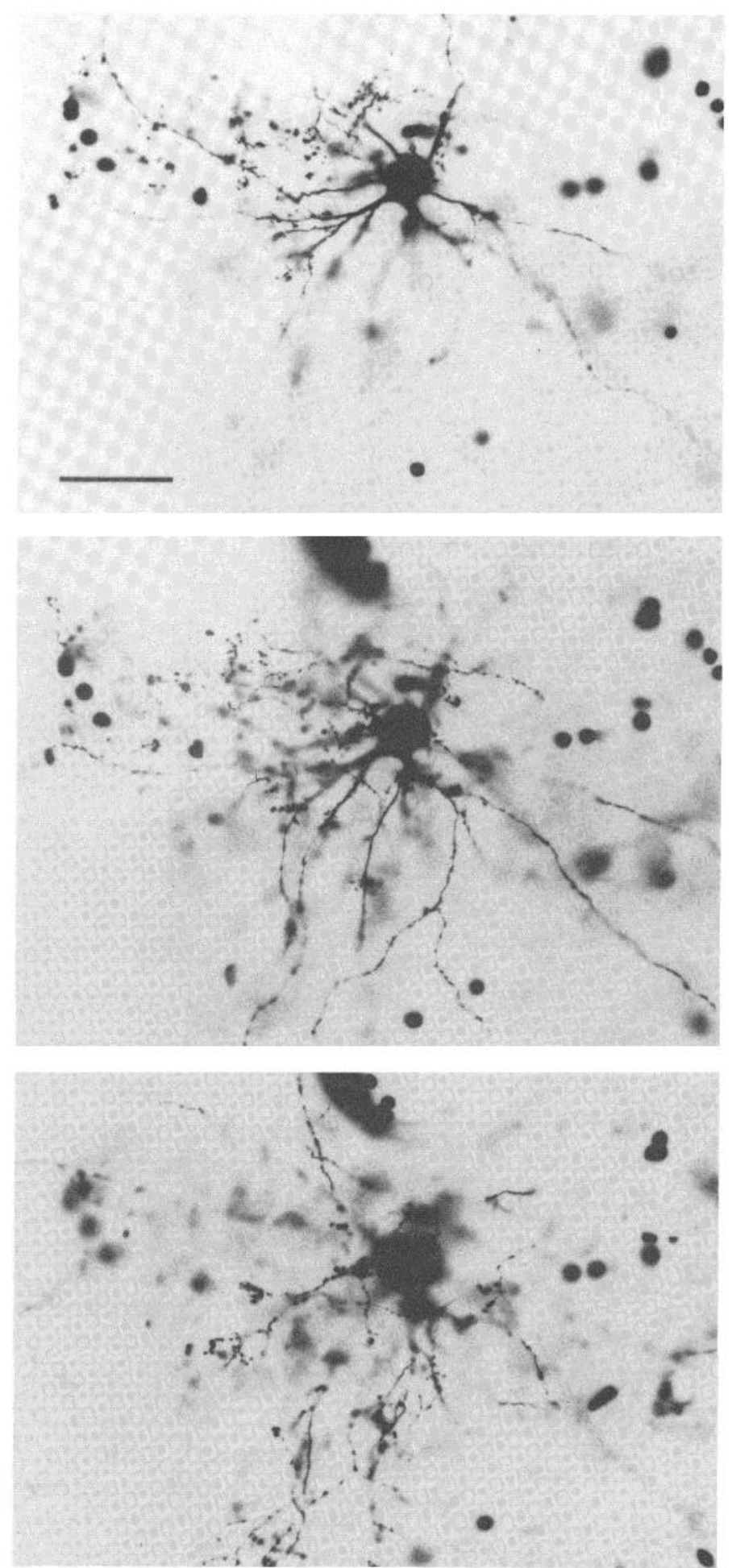

Figure 5. Photomicrographs of the deprived geniculate neuron traced in Figure $4 B$. The three photomicrographs represent the same field of view at different focal planes. The scale bar in the top photomicrograph is $50 \mu \mathrm{m}$ and applies also to the other photomicrographs. This cell was physiologically identified as an abnormal Y-cell (see text), and its morphology is characterized by unusually sinuous and varicose dendrites not seen in any normal geniculate neuron. these abnormal cells were small, and while the proximal dendrites issued from the somata in a fashion typical of Y-cells (i.e., the proximal dendrites were fairly thick and displayed a radial symmetry in their distribution), they became extremely thin and beaded and took an exceptionally convoluted course. The rich dendritic arbors appeared as a tangled web of fine processes. No geniculate neurons seen in normal cats exhibited similar morphology.

Unresponsive cells with abnormal morphology. Two cells exhibited no detectable responses to visual stimuli despite about $1 \mathrm{hr}$ of testing. Since these neurons were recorded immediately following the recording of normally responsive cells, the expected receptive field locations of the neurons were at least approximately known. To our knowledge, such completely unresponsive cells have never been reported in the A laminae of normal cats, and we have never seen such cells in similar studies of normal cats. One of these cells also exhibited no response to optic chiasm stimulation, but the other responded erratically, with latencies ranging from 1.3 to $1.9 \mathrm{msec}$. Although only 2 such unresponsive cells were filled with HRP successfully, others were encountered in the course of this study.

Figure 6 shows the morphological characteristics of these cells, and they were not obviously different from

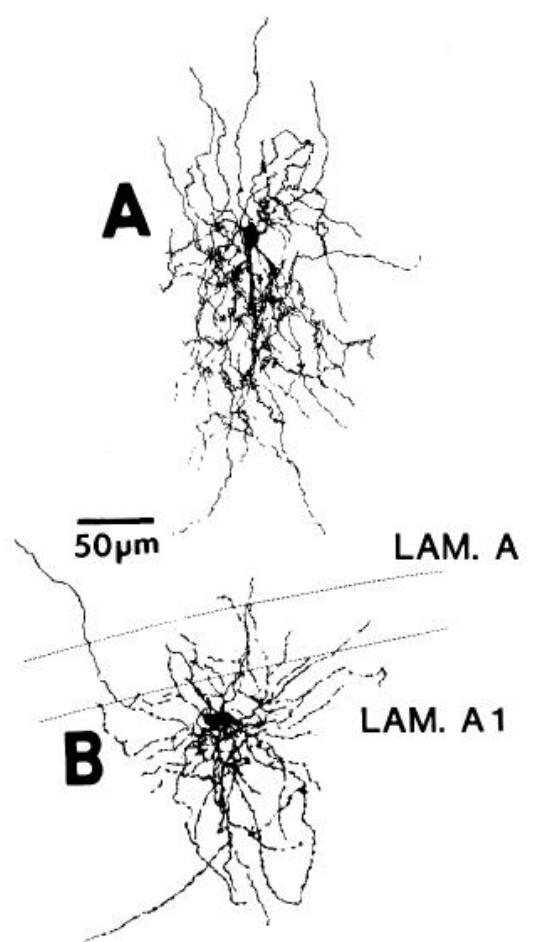

Figure 6. Camera lucida drawings of 2 visually unresponsive cells from laminae innervated by the deprived eye in monocularly sutured cats. In both cases, the receptive fields of neighboring cells were mapped immediately prior to isolation of these neurons so that the expected receptive field position was known. However, detailed testing revealed no visual responsiveness. The cell in $A$ showed weak responsiveness to electrical activation of the optic chiasm, and the cell in $B$ showed no responsiveness to such stimulation. Note the sinuous and varicose dendrites similar to those of the abnormal Y-cells illustrated in Figures 4 and 5. Laminar boundaries are indicated by the dashed lines. 
those of the two abnormal Y-cells illustrated in Figures 4 and 5 . The possibility exists that these 4 cells shown in Figures 4 to 6 represent Y-cells with varying degrees of abnormality, ranging from somewhat reduced responsiveness to complete unresponsiveness. Consistent with this suggestion was the occasional appearance of short latency $(1.3-\mathrm{msec})$ responses to optic chiasm stimulation in 1 of the visually unresponsive cells.

Neurons with X-cell physiology and Y-cell morphology. Perhaps the most surprising and interesting abnormality was found for 4 other cells that exhibited normal $\mathrm{X}$-cell responses but had morphological features characteristic of normal Y-cells (see Figs. 2, 7, and 8). They had somata within the size range of normal Y-cells and larger than most normal X-cells (although only 1 of these was larger than the largest normal X-cell). They also had thick, cruciate dendrites arranged in a radially symmetric arbor with a few, spine-like appendages. Some of these dendrites crossed laminar borders, a characteristic typical of Y-cells but not X-cells in normal cats (Friedlander et al., 1981). These morphological features are common to the class 1 cell described by Guillery (1966) and have not been seen in any of the 35 normal X-cells recovered to date. Such morphology is almost always associated with Y-cells, although it is seen rarely with physiologically unclassified cells (Friedlander et al., 1981). Despite our small data base, the fraction of class 1 cells among deprived X-cells is reliably greater than that seen among normal X-cells (4 of 17 versus 0 of $35 ; p<0.02$ on a $\chi^{2}$ test).

Soma size distribution. Figure 2 shows the soma sizes of normal geniculate $\mathrm{X}$ - and $\mathrm{Y}$-cells from the A laminae
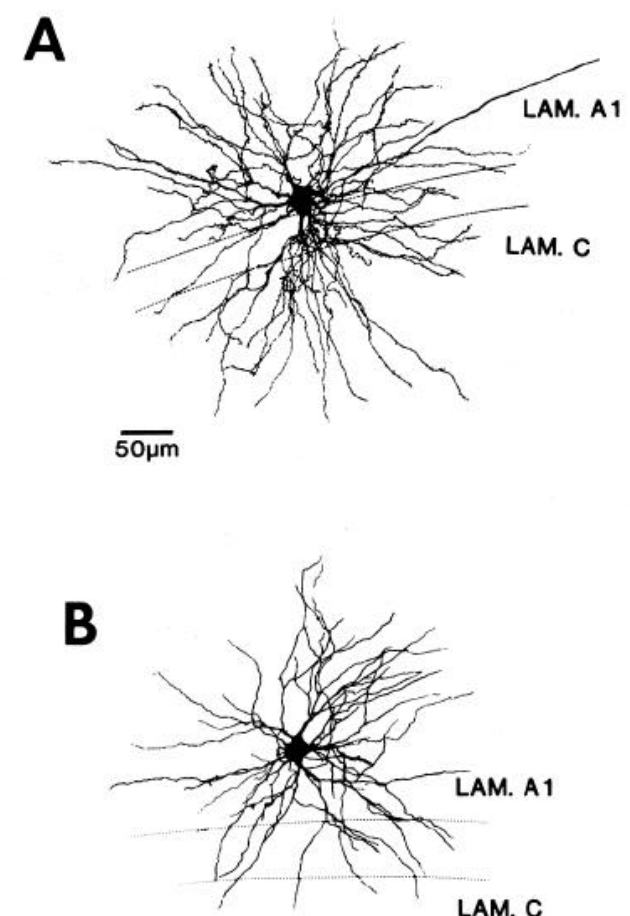

Figure 7. Camera lucida drawings of cells from laminae innervated by the deprived eye with normal X-cell physiological properties but morphology typical of normal Y-cells. Laminar boundaries are indicated by the dashed lines. compared with the sizes of the deprived cells from the present study. Little or no abnormality can be seen for the deprived X-cell soma size distribution $(p>0.1$ on a Mann-Whitney $U$ test), but deprived Y-cells are significantly smaller than normal ( $p<0.001$ on a Mann-Whitney $U$ test). Thus, the abnormally small somata associated with deprived geniculate neurons may be a deficit primarily limited to Y-cells.

\section{Discussion}

It is clear that monocular lid suture causes the development of abnormal properties among many neurons of the cat's lateral geniculate nucleus. Furthermore, development of the Y-cell pathway seems to be affected much more seriously by the deprivation than does the X-cell pathway (Sherman et al., 1972; Jones and Berkley, 1977; LeVay and Ferster, 1977; Kratz et al., 1978b; Lin and Sherman, 1978; Geisert et al., 1980; Mitzdorf and Singer, 1980; Derrington and Hawken, 1981). Nearly all of the deprived neurons with normal morphology and response properties are X-cells. Many deprived Y-cells seem to develop abnormal structural and/or functional properties, and some deprived neurons develop X-cell physiological properties despite morphology that suggests that they might normally be expected to develop as Y-cells.

\section{$X$-cell development}

As noted above, the structure-function properties of the majority of deprived X-cells develop normally. The only physiological deficit described for these cells is a modest reduction in spatial acuity (Hoffmann and Sireteanu, 1977; Lehmkuhle et al., 1980b; but see Shapley and So, 1980; Derrington and Hawken, 1981).

A striking departure from the normal structure-function relationships for some deprived X-cells is the development of morphological class 1 features. This is described in more detail below. At present, we have insufficient data to determine if the physiological properties of these class $1 \mathrm{X}$-cells differ from those of deprived Xcells with morphological features more appropriate for normal X-cells. Also, since there is reason to believe that, in normal cats, Y-cells and large cells (but not X-cells) project to cortical area 18 (Garey and Powell, 1967; Stone and Dreher, 1973; LeVay and Ferster, 1977), the possibility exists that these class $1 \mathrm{X}$-cells represent a geniculocortical X-cell pathway to area 18 that is not present normally. It is interesting in this regard that the few deprived geniculate neurons reported by Lin and Sherman (1978) to project to area 18 have such large somata that, according to Figure 2, many could be X-cells. A similar possibility exists regarding geniculostriate inputs. Evidence from the normal cat suggests that $\mathrm{X}$ - and $\mathrm{Y}$ cells terminate, respectively, in layer IVb and layer IVa of area 17 (Ferster and LeVay, 1978; Gilbert and Wiesel, 1979). Monocular deprivation might create an anomalous $\mathrm{X}$-cell pathway to layer IVa from deprived geniculate laminae.

\section{Y-cell development}

The deprived Y-cell pathway is disrupted rather seriously at the level of the lateral geniculate nucleus. At least two and possibly three or more different processes 

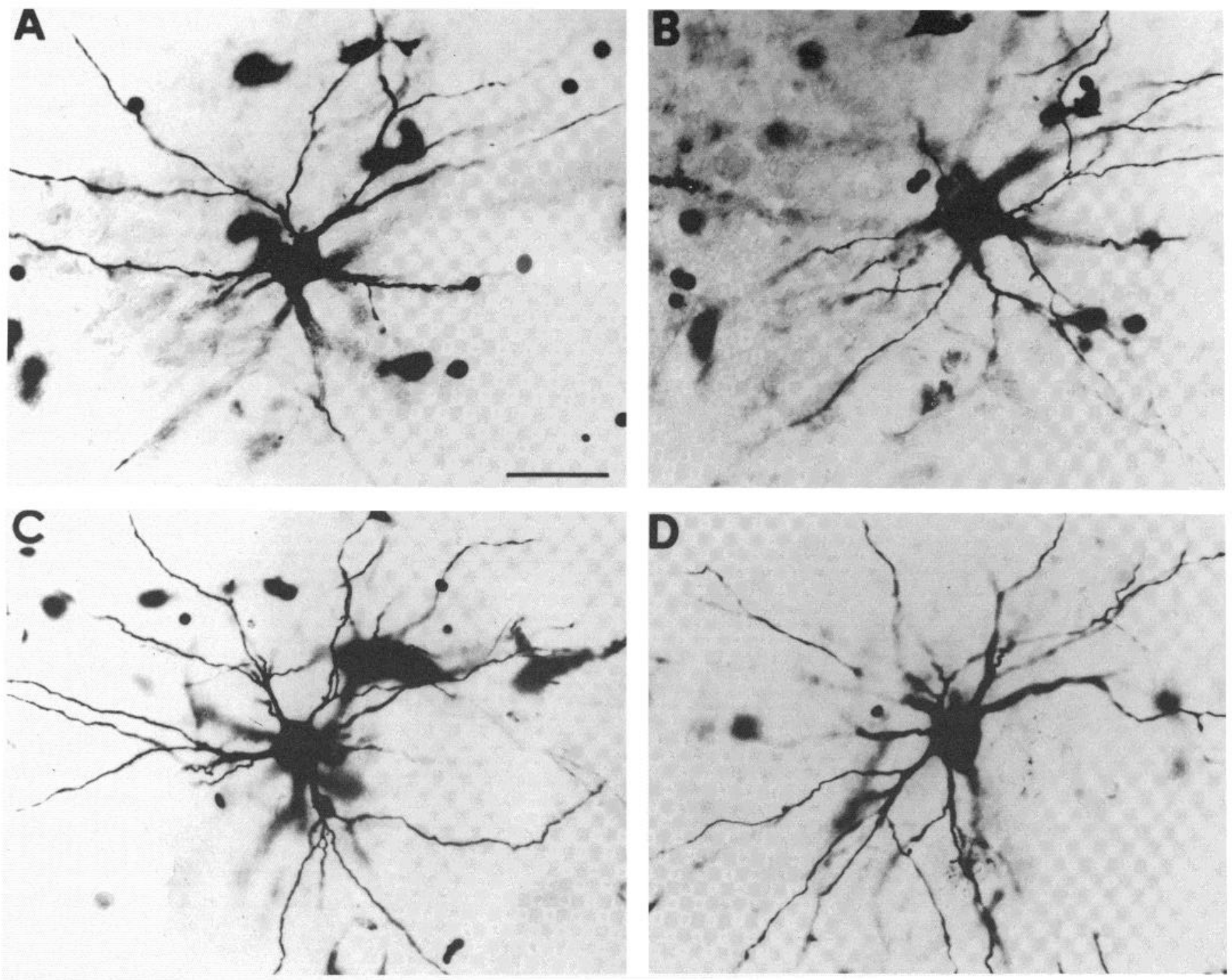

Figure 8. Photomicrographs of geniculate neurons of the same morphological class (i.e., class 1 cells as described by Guillery, 1966). $A$ and $B$, Two focal planes of the same field of view of a deprived neuron with normal X-cell physiological characteristics. This cell also is illustrated in Figure $7 B$. $C$, Another deprived neuron with normal X-cell physiological characteristics. This cell also is illustrated in Figure $7 A$. $D$, A Y-cell from a normal cat. This cell is the Y-cell illustrated in Figure 1 . The $s c a l e$ bar in $A$ is $50 \mu \mathrm{m}$ and applies as well to $B$ to $D$.

seem to occur during development to produce these deficits.

Small Y-cells. Some physiologically normal Y-cells develop in deprived laminae with apparently normal morphology except for unusually small somata. Their normal response properties suggest normal retinogeniculate transmission. The significance of their small somata is less clear. However, several authors have suggested that geniculate soma size is related to the size of that neuron's terminal axonal field in the cortex (Guillery and Stelzner, 1970; Guillery, 1972; Hubel et al., 1977; Shatz and Stryker, 1978; LeVay et al., 1980). A reduction in the soma size of these Y-cells consequently suggests the possibility of their reduced geniculocortical transmission.

Abnormal Y-cells. Some cells have been identified as abnormal Y-cells due to their generally poor or variable responses that, when present, typify Y-cells. This suggests a disruption of retinogeniculate and/or intrageniculate transmission. The morphology of these cells is consistent with this since their dendrites appear to be so pathological (see Figs. 4 and 5) that they suggest a possible postsynaptic site for deficits in retinogeniculate transmission. The unresponsive cells illustrated in Figure 6 have such similar morphology to the abnormal Y-cells that we shall tentatively group these cells with those of Figures 4 and 5 as representing different degrees of the same process. It is also possible that the least affected Ycells have fairly normal physiology and morphology except for reduced soma size and that all of these abnormalities represent varying degrees of the same process.

Deprived geniculate neurons with abnormal response properties have been described previously. Indeed, Wiesel and Hubel (1963) noted that 4 of 19 (21\%) deprived 
geniculate cells studied in detail in laminae $\mathrm{A}$ and $\mathrm{A}_{1}$ displayed abnormal physiology. Kratz et al. (1978b) described many cells with abnormal responses among deprived neurons of the medial interlaminar nucleus, and nearly all of these neurons normally are Y-cells (Kratz et al., 1978a). As noted under "Results," we encountered many more of these than are represented by the few that were filled with HRP successfully and recovered.

Class $1 \mathrm{X}$-cells. Since, in normal cats, cells with the morphology of class 1 cells (Guillery, 1966) are almost always associated with Y-cells and never with X-cells (Friedlander et al., 1981), the appearance of significant numbers of class $1 \mathrm{X}$-cells in deprived laminae represents a substantial developmental anomaly. A number of interpretations are possible, but the most likely seems to be that geniculate cells that, under normal circumstances, accept Y-cell input from the optic tract accept and/or retain $\mathrm{X}$-cell input instead due to the visual deprivation. This implies that deprived laminae actually contain more $\mathrm{X}$-cells and fewer Y-cells than normal, a possibility that Kalil and Worden (1978) have already suggested for darkreared cats. We can suggest at least three mechanisms by which this might occur.

First, a reinnervation of some $\mathrm{Y}$-cells may occur during development. That is, deprivation might promote a process that causes some class 1 neurons to lose $\mathrm{Y}$-cell input from the optic tract and obtain X-cell input instead. Although possible, there seems to be little support for such a process from other studies of neural development.

Second, neural development often proceeds in a manner whereby excessive axonal projections are "pruned" during development to produce the specific and appropriate connections (see Rakic, 1976; Brown et al., 1976; LeVay et al., 1978, 1980; Purves, 1980; Purves and Lichtman, 1980). Perhaps class 1 cells receive optic tract input from both X-and Y-cells during development. Normally, the Y-cell input develops dominance and most of these become Y-cells, although a few may remain unclassified (Cleland et al., 1971; Hoffmann et al., 1972; Friedlander et al., 1981). Deprivation may alter the process and permit X-cell input to predominate in many cases. How this might occur is considered below.

Third, because our sample of normal neurons is limited due to the difficulty of obtaining large numbers of physiologically identified, HRP-filled neurons, the possibility exists that class $1 \mathrm{X}$-cells occasionally occur in normal tissue. They might be found relatively more frequently in deprived laminae if many of the class $1 \mathrm{Y}$-cells fail to develop normal responsiveness and are not sampled. This possibility can be reasonably discarded only after a larger sample of normal X-cells fails to demonstrate any with class 1 morphology.

Mechanisms of $Y$-cell development. Two developmental mechanisms can be considered to account for the profound effect of lid suture upon geniculate Y-cell development. First, there is considerable evidence that abnormal binocular interactions through a process of binocular competition affect Y-cell development (Sherman et al., 1972, 1975; Lehmkuhle et al., 1980b; for a more detailed discussion of this, see Sherman et al., 1974; Sherman and Spear, 1982). This conclusion derives from the observation that, in the deprived monocular segments where abnormal binocular interactions cannot occur, Y- cells develop completely normally; only in the deprived binocular segment are normal Y-cells difficult to record. The abnormal and unresponsive Y-cells with bizarre morphology and/or normal Y-cells with small somata may be a product of such a mechanism.

Second, the presence of deprived X-cells with class 1 morphology suggests the possibility of competition between X-and Y-cell optic tract terminals for postsynaptic sites on these class 1 cells. According to this hypothesis, a normal visual environment would favor Y-cell inputs, and deprivation would favor X-cell inputs. It is interesting to note that some physiological properties of geniculate X-cells, and thus optic tract X-cell inputs, normally mature earlier than do Y-cell and Y-cell inputs (Norman et al., 1977; Daniels et al., 1978). Perhaps normal activity among later developing $\mathrm{Y}$-cell inputs is needed to enable them to dominate the class 1 cells. We must emphasize that this speculation is little more than a working hypothesis at present to explain the observation of deprived $\mathrm{X}$-cells with class 1 morphology.

Functional significance of the loss of recorded Y-cells. Although many studies have reported a loss of recorded Y-cells in deprived geniculate laminae of cats (Sherman et al., 1972, 1975; Kratz et al., 1978b; Hoffmann and Hollander, 1978; Eysel et al., 1979; Geisert et al., 1980; Mower et al., 1981; Zetlan et al., 1981), the interpretation of these data has been unclear. The possibility that this observation represents a severe functional abnormality in the deprived Y-cell pathway has been challenged with the suggestion that it represents nothing more than an electrode sampling artifact (Shapley and So, 1980; but see Friedlander et al., 1981, for a discussion of this). That is, the deprived Y-cells may be morphologically small but physiologically normal.

In order to avoid the potential pitfalls of single cell sampling procedures, several investigators have used evoked potential techniques to study the effects of monocular suture on geniculocortical transmission. Jones and Berkley (1977) found that evoked cortical responses to high, but not low, flicker rates were reduced selectively by monocular suture, and Y-cells are more sensitive than are X-cells to such high flicker rates. Eysel et al. (1979) found a reduction and temporal dispersion of the response of fast conducting (Y-cell) geniculocortical afferents from the deprived eye (see Fig. $1 F$ of their paper). Snyder and Shapley (1979) reported that evoked cortical responses from stimulation of the deprived eye were most affected when low, but not high, spatial frequencies were used as the stimulus, and Y-cells are more sensitive than are X-cells to such low spatial frequencies. Finally, Mitzdorf and Singer (1980) found that the faster conducting (Y-cell) geniculocortical pathway to areas 17 and 18 was considerably more affected by monocular suture than was the slower conducting (X-cell) pathway to area 17 . All of these evoked potential studies thus indicate deficits in properties usually ascribed to Y-cells.

Morphological studies also suggest that geniculate Ycells are more affected by early monocular lid suture than are X-cells. Retrograde transport of HRP injected into cortical area 17 or 18 leads to similar conclusions (Garey and Blakemore, 1977; Lin and Sherman, 1978). Shatz and Stryker (1978) noted in orthograde studies of the geniculostriate pathway that the deprived axons en- 
tering layer IVa of area 17 grow less than do those entering layer IVb. Finally, LeVay and Ferster (1977) argued that the presence of cytoplasmic laminated bodies marks X-cells with class 2 morphology, and their absence in larger somata marks Y-cells with class 1 morphology. Based on this, these authors found in deprived laminae both that there is a slight reduction in Y-cell numbers and also that the more abnormally small somata lack cytoplasmic laminated bodies and are thus likely to be Y-cells. It is interesting to note that LeVay and Ferster (1977) may have underestimated the loss of Y-cells from deprived laminae, since they assumed that all remaining class 1 cells were Y-cells. Our data suggest that some of these deprived class 1 cells were X-cells.

There seem to be too many morphological and physiological changes that suggest functional alterations in the Y-cell pathway (reviewed in detail in Sherman and Spear, 1982) to be consistent with a simple electrode sampling explanation. The present results also make it extremely unlikely that deprived geniculate neurons develop normally except for reduced soma sizes. Most X-cells and otherwise normal Y-cells with small somata develop essentially normal response properties. While these smaller Y-cells may be sampled less frequently electrophysiologically than their larger counterparts in nondeprived laminae, evidence from normal geniculate neurons suggests that soma size has rather little effect upon electrode sampling characteristics (Friedlander et al., 1981). In any case, cells with abnormal structure-function relationships represent genuine developmental anomalies in deprived laminae that have little to do with electrode sampling characteristics.

\section{Conclusions}

Although a number of conclusions can be drawn from these data, we must re-emphasize their qualitative nature and the limited number of neurons from which these conclusions are derived. More quantitative conclusions regarding the effects of lid suture upon the development of structure and function in geniculate neurons must await further data, and our experiments are still being pursued with this in mind. Nonetheless, a number of points seem clear from these results.

Lid suture prevents development of normal relationships between structure and function for many geniculate neurons. $\mathrm{X}$-cells seem much less affected by deprivation than do Y-cells, and most deprived X-cells develop roughly normal structure and function. Only one deprived Y-cell in our sample developed normal morphology and response properties. The vast majority of $\mathrm{Y}$-cells seems to develop quite abnormally. A further abnormality in the Y-cell pathway is suggested by the presence of neurons with the physiology of $\mathrm{X}$-cells and morphology of Y-cells. A combination of abnormal binocular competition and relatively late maturation of geniculate $Y$-cells reiative to $\mathrm{X}$-cells might account for many of these deficits.

\section{References}

Brown, M. C., J. K. S. Jansen, and D. Van Essen (1976) Polyneuronal innervation of skeletal muscle in new-born rats and its elimination during maturation. J. Physiol. (Lond.) 261: $387-422$.
Cleland, B. G., M. W. Dubin, and W. R. Levick (1971) Sustained and transient neurons in the cat's retina and lateral geniculate nucleus. J. Physiol. (Lond.) 217: 473-496.

Daniels, J. D., J. D. Pettigrew, and J. L. Norman (1978) Development of single neuron responses in kitten's lateral geniculate nucleus. J. Neurophysiol. 41: 1373-1393.

Derrington, A. M., and M. J. Hawken (1981) Spatial and temporal properties of cat geniculate neurons after prolonged deprivation. J. Physiol. (Lond.) 314: 107-120.

Enroth-Cugell, C., and J. G. Robson (1966) The contrast sensitivity of retinal ganglion cells of the cat. J. Physiol. (Lond.) 187: $517-552$.

Eysel, U. Th., O. J. Grusser, and K. -P. Hoffmann (1979) Monocular deprivation and the signal transmission by $\mathrm{X}$ - and Y-neurons of the cat lateral geniculate nucleus. Exp. Brain Res. 34: 521-539.

Ferster, D., and S. LeVay (1978) The axonal arborizations of lateral geniculate neurons in the striate cortex of the cat. J. Comp. Neurol. 182: 923-944.

Friedlander, M. J., C. -S. Lin, and S. M. Sherman (1979) Structure of physiologically identified $\mathrm{X}$ - and $\mathrm{Y}$-cells in the cat's lateral geniculate nucleus. Science 204: 1114-1117.

Friedlander, M. J., C. -S. Lin, L. R. Stanford, and S. M. Sherman (1981) Morphology of functionally identified neurons in lateral geniculate nucleus of the cat. J. Neurophysiol. 46: 80-129.

Garey, L. J., and C. Blakemore (1977) Monocular deprivation: Morphological effects on different classes of neurons in the lateral geniculate nucleus. Exp. Brain Res. 28: 259-278.

Garey, L. J., and T. P. S. Powell (1967) The projection of the lateral geniculate nucleus upon the cortex of the cat. Proc. R. Soc. Lond. (Biol.) 169: 107-126.

Garey, L. J., R. A. Fisken, and T. P. S. Powell (1973) Effects of experimental deafferentation on cells in the lateral geniculate nucleus of the cat. Brain Res. 52: 363-369.

Geisert, E. E., P. D. Spear, S. R. Zetlan, and A. Langsetmo (1982) Recovery of Y-cells in the lateral geniculate nucleus of monocularly deprived cats. J. Neurosci., in press.

Gilbert, C. D., and T. N. Wiesel (1979) Morphology and intracortical projections of functionally characterized neurones in the cat visual cortex. Nature 280:120-125.

Guillery, R. W. (1966) A study of Golgi preparations from the dorsal lateral geniculate nucleus of the adult cat. J. Comp. Neurol. 238: 21-50.

Guillery, R. W. (1972) Binocular competition in the control of geniculate cell growth. J. Comp. Neurol. 144: 117-130.

Guillery, R. W., and D. J. Stelzner (1970) The differential effects of unilateral lid closure upon the monocular and binocular segments of the dorsal lateral geniculate nucleus in the cat. J. Comp. Neurol. 139: 413-422.

Hickey, T. L. (1980) Development of the dorsal lateral geniculate nucleus in normal and visually deprived cats. J. Comp. Neurol. 189: 467-481.

Hickey, T. L., P. D. Spear, and K. E. Kratz (1977) Quantitative studies of cell size in the cat's dorsal lateral geniculate nucleus following visual deprivation. J. Comp. Neurol. 172: 265-282.

Hochstein, S., and R. M. Shapley (1976) Quantitative analysis of retinal ganglion cell classifications. J. Physiol. (Lond.) 262: 237-264.

Hoffmann, K. -P., and H. Hollander (1978) Physiological and morphological changes in cells of the lateral geniculate nucleus in monocularly deprived and reverse sutured cats. $J$ Comp. Neurol. 177: 145-158.

Hoffmann, K. -P., and R. Sireteanu (1977) Interlaminar differences in the effects of early and late monocular deprivation in the visual acuity of cells in the LGN of the cat. Neurosci. Lett. 5: 171-175.

Hoffmann, K. -P., J. Stone, and S. M. Sherman (1972) Relay of receptive field properties in dorsal lateral geniculate nucleus 
of the cat. J. Neurophysiol. 35: 518-531.

Hubel, D. H., T. N. Wiesel, and S. LeVay (1977) Plasticity of ocular dominance columns in monkey striate cortex. Philos. Trans. R. Soc. Lond. (Biol.) 278: 377-409.

Jones, K. R., and M. A. Berkley (1977) Distribution and temporal response characteristics of evoked potentials in the visually deprived cat. Brain Res. 130: 572-578.

Kalil, R. (1980) A quantitative study on the effects of monocular enucleation and deprivation on cell growth in the dorsal lateral geniculate nucleus of the cat. J. Comp. Neurol. 189: 483-524.

Kalil, R., and I. Worden (1978) Cytoplasmic laminated bodies in the lateral geniculate nucleus of normal and dark reared cats. J. Comp. Neurol. 178: 469-485.

Kratz, K. E., S. V. Webb, and S. M. Sherman (1978a) Studies of the cat's medial interlaminar nucleus: A subdivision of the dorsal lateral geniculate nucleus. J. Comp. Neurol. 181: 601614.

Kratz, K. E., S. V. Webb, and S. M. Sherman (1978b) Effects of early monocular lid suture upon neurons in the cat's medial interlaminar nucleus. J. Comp. Neurol. 181: 615-626.

Lehmkuhle, S., K. E. Kratz, S. C. Mangel, and S. M. Sherman (1980a) Spatial and temporal sensitivity of X-and Y-cells in dorsal lateral geniculate nucleus of the cat. J. Neurophysiol. 43: $520-541$.

Lehmkuhle, S., K. E. Kratz, S. C. Mangel, and S. M. Sherman (1980b) Effects of early monocular lid suture on spatial and temporal sensitivity of neurons in dorsal lateral geniculate nucleus of the cat. J. Neurophysiol. 43: 542-556.

LeVay, S., and D. Ferster (1977) Relay cell classes in the lateral geniculate nucleus of the cat and effects of visual deprivation. J. Comp. Neurol. 172: 563-584.

LeVay, S., M. Stryker, and C. J. Shatz (1978) Ocular dominance columns and their development in layer IV of the cat's visual cortex: A quantitative study. J. Comp. Neurol. 179: 223-244.

LeVay, S., T. N. Wiesel, and D. H. Hubel (1980) The development of ocular dominance columns in normal and visually deprived monkeys. J. Comp. Neurol. 191: 1-51.

Lin, C. S., and S. M. Sherman (1978) Effects of early monocular lid suture upon the development of relay cell classes in the cat's lateral geniculate nucleus. J. Comp. Neurol. 181: 809831.

Mitzdorf, U., and W. Singer (1980) Monocular activation of visual cortex in normal and monocularly deprived cats: An analysis of evoked potentials. J. Physiol. (Lond.) 304: 203220.

Mower, G. D., J. L. Burchfiel, and F. H. Duffy (1981) The effect of dark rearing on the development and plasticity of the lateral geniculate nucleus. Dev. Brain Res. 1: 418-424.
Norman, J. L., J. D. Pettigrew, and J. D. Daniels (1977) Early development of $\mathrm{X}$-cells in kitten lateral geniculate nucleus. Science 198: 202-204.

Purves, D. (1980) Neuronal competition. Nature 287: 585-586.

Purves, D., and J. W. Lichtman (1980) Elimination of synapses in the developing nervous system. Science 210: 153-157.

Rakic, P. (1976) Prenatal genesis of connections subserving ocular dominance in the rhesus monkey. Nature 261: 467471.

Shapley, R., and Y. T. So (1980) Is there an effect of monocular deprivation on the proportion of $\mathrm{X}$ - and Y-cells in the cat lateral geniculate nucleus? Exp. Brain Res. 39: 41-48.

Shatz, C. J., and M. P. Stryker (1978) Ocular dominance in layer IV of the cat's visual cortex and the effects of monocular deprivation. J. Physiol. (Lond.) 281: 267-283.

Sherman, S. M., and P. D. Spear (1982) Organization of the visual pathways in normal and visually deprived cats. Physiol. Rev., in press.

Sherman, S. M., K. -P. Hoffmann, and J. Stone (1972) Loss of a specific cell type from dorsal lateral geniculate nucleus in visually deprived cats. J. Neurophysiol. 35: 532-541.

Sherman, S. M., R. W. Guillery, J. H. Kaas, and K. J. Sanderson (1974) Behavioral, electrophysiological and morphological studies of binocular competition in the development of the geniculocortical pathways of cats. J. Comp. Neurol. 158: 118.

Sherman, S. M., J. R. Wilson, and R. W. Guillery (1975) Evidence that binocular competition affects the postnatal development of Y-cells in the cat's lateral geniculate nucleus. Brain Res. 100: 441-444.

Snyder, A., and R. Shapley (1979) Deficits in the visual evoked potentials of cats as a result of visual deprivation. Exp. Brain Res. 37: 73-86.

Stanford, L. R., M. J. Friedlander, and S. M. Sherman (1981) Morphology of physiologically identified W-cells in the C laminae of the cat's lateral geniculate nucleus. J. Neurosci. 1: 578-584.

Stone, J., and B. Dreher (1973) Projection of X-and Y-cells of cat's lateral geniculate nucleus to areas 17 and 18 of visual cortex. J. Neurophysiol. 36: 551-567.

Wiesel, T. N., and D. H. Hubel (1963) Effects of visual deprivation on morphology and physiology of cells in the cat's lateral geniculate body. J. Neurophysiol. 26: 978-993.

Wilson, P., M. Rowe, and J. Stone (1976) Properties of relay cells in cat's lateral geniculate nucleus: A comparison of Wcells with X- and Y-cells. J. Neurophysiol. 39: 1193-1209.

Zetlan, S. R., P. D. Spear, and E. E. Geisert (1981) The role of cortico-geniculate projections in the loss of Y-cells in monocularly deprived cats. Vision Res. 21: 1035-1039. 